\title{
Exploring Alternatives of Accounting for Environmental Liabilities in the Company's Balance Sheet
}

\author{
Fernando A. Bortuluzi, Feni Agostinho, Cecília Maria Villas Boats Almeida, \\ Silvia Bonilla, and Biagio F. Gianetti \\ Post-graduation Program on Production Engineering, Paulista University (UNIP), \\ Rua Dr. Bacelar 1212 CEP 04026-002 São Paulo, Brazil \\ \{Feni Agostinho, feniagostinho\}@gmail.com
}

\begin{abstract}
Environmental concerns have recently reached the stock market, in which investors want analyze the company's related-risks in causing environmental damages. Usually, the Company's Balance Sheet (CBS) is summarized, disallowing a clear interpretation of environmental issues. Methods used to valuate environmental liabilities are often subjective, which create communication problems. The aims of this work are (i) to explore alternatives for CBS structural presentation to clearly represent environmental liabilities, which allow an efficient communication with society and investors, and (ii) to assess a methodological alternative of valuating environmental liabilities under economical terms. The "Petrobras" S.A. Brazilian Oil Company is taken as a case study by accounting its oil spill related-incidents occurred in 2000 yr. Results show that an improved CBS structure should represent the company's environmental related-issues. Additionally, emergy accounting appears as a powerful alternative to replace/substitute contingent valuation to quantify environmental liabilities under economic terms.
\end{abstract}

Keywords: environmental liabilities, emergy accounting, integrated report, Petrobras S.A, oil spill.

\section{Introduction}

History has many examples of companies that passed from successful to failure examples, such as the American Company Enron in the 90's, and, recently, the American Lehman Brothers and the Brazilian EBX group. These examples expose a similar problem: the weakness of the current model to represent the company's balance sheet (CBS). Since 2010, the top-100 worldwide companies are discussing the creation of a new balance sheet structure, considering an integrated thinking and a more holistic perspective. This proposal is being labeled as Integrated Report [1, which main is to clearly represent the company's targets at long term and the strategies to get there. In this sense, several important aspects as human, natural, and intellectual capitals are also being considered instead of exclusively financial results. The Integrated Report, which intends to be in harmony with sustainable development, is severely criticized in some studies [2] due to the difficulties in integrating biophysical accounting with the many existing cores of financial accounting conventions. 
Similarly to Integrated Reports, some studies [3] have already argued that provisioning for environmental damages should be present in the CBS, otherwise, distorted information is obtained in which the liabilities are undervalued and equity overvalued. Not accounting for liabilities at the same year of occurrence - usually due to judicial delay - can also affect the company's future performance and result in economical losses; and investors will not have in traditional CBS enough indicators for the efficient evaluation of the company's economical performance, especially regarding to judge risks on investing in the company.

The traditional financial accounting techniques are unable to measure resources and services provided by biosphere, as well as all the environmental impacts caused by releasing high concentrated wastes on natural environment. This accounting limitation is due to a lack of market value of environmental goods and services. Some studies [4] have warned about the need for developing and standardizing trustable methodologies to quantify the environmental performance of companies. The valuation of environmental liabilities, for a long time, is realized under subjective approaches, which do not represent real values for repair or substitution [5]. In this sense, the environmental liabilities must be objectively quantified (i.e. under biophysical approaches) to be included into the CBS. Efforts were made to quantify liabilities by using eMergy methodology [6], and to integrate eMergy with bookkeeping techniques [7, 8]. However, none of them have explored the inclusion of the quantified liabilities into the CBS in a the way they can be accessible to interested pubic and clearly represented by scientifically accepted methods.

This work explores alternatives for representing the environmental liabilities into the CBS, focusing on an efficient communication about the company's economical performance for the general society and investors. For this, raw data from [3] is used considering as case study the published 2000's balance sheet of the Brazilian Oil Company "Petrobras" S.A. Emergy accounting [5] is suggested as an alternative scientific methodology in providing a biophysical view (biophysical indicators?) to quantify environmental liabilities.

\section{Methodology}

\subsection{Case Study Description}

The main goal of this paper is to explore alternatives to accounting for the environmental liabilities in the company's balance sheet (CBS), through a case study. The case study is considered mandatory to solidify the ideas under discussion and to point out how and where the liabilities could be estimated and included. Negative externalities caused by oil spill incidents are considered due to their high impact on environment and society. It is worth to say that Petrobras S.A. is signatory of the International Integrated Reporting Council. The oil spill incidents that occurred in Brazil $2000 \mathrm{yr}$ were accounted and described in detail by [3]. In short, about 78,740 oil barrels spilled under three different incidents, each one resulting in different damages. For calculation purposes, the kind of environmental damages were considered the same in all incidents, differing only on the impact level. This is valid 
because this work is a first attempt in assessing alternatives for including damages into the CBS instead of calculating precise value for environmental liabilities.

\subsection{Studied Alternatives for Presenting Environmental Liabilities into the Balance Sheet}

Two alternatives of presenting environmental liabilities into the company's balance sheet (CBS) are assessed and compared to the traditional CBS labeled as Baseline; considering the current Brazilian law for financial accounting techniques (no. $6,404 / 1976$ ), as well as recent alterations by laws no. 11,638/2007 and 11,941/2009. It is worth to say that these alterations aimed to get closer and be compared with definitions and structures of international rules. The Baseline and the two alternatives discussed in this paper are the following:

(a) Baseline: Traditional accounting approach considered in Brazil according to law no. 6,404/1976. This approach does not foresee any inclusion and/or disclosure of environmental liabilities into the CBS.

(b) Alternative \#1: Accounting approach suggested by [3] aiming to improve the regulations of law no. 6,404/1976. These authors intended to establish an alternative way to include the environmental liabilities into the CBS by expressing clearly the related economic amount and its influence on the company's "equity" indicator. For this, the company economic investment on environmental issues is included into the "assets" group of the balance sheet, and the economical obligation (i.e. penalties and indemnities) into the "liabilities" group.

(c) Alternative \#2: The suggested accounting approach in this work according to law no. 6,404/1976 and its alterations by laws no. $11,638 / 2007$ and 11,941/2009. The intention is to establish a clearer structure for CBS compared to that proposed by [3]. Initially, it is emphasized that alterations of law no. 6,404/1976 have created a category "intangible" within the subgroup "noncurrent assets", which represents the value of immaterial assets (e.g. exploration rights, copyrights, franchise rights, trademarks, licenses, and softwares). Although considering the company's reduction accounts (e.g. mark depreciation and license losses), the creation of "intangibles" could raise the doubt about the need of a counterpart into the "liabilities" and "equity" groups of balance sheet to evidence these impacts, because the existence of "intangibles" allows the company to incur in financial debts. This doubt is valid because there is no regulation about a counterpart from intangible obligations incurred by company, as example, the environmental pollution, social responsibility, among others. This aspect is mainly important in a scenario in which the "liabilities" are higher than "assets", which results in a negative influence on company's "equity". At any case, a clear presentation of this aspect within the CBS is mandatory.

\subsection{Studied Alternatives for Environmental Damages Valuation}

There are some methods most accepted and used to estimated economic values for environmental attributes, including the contingent valuation. Although the role of using contingent valuation in the assessment of natural resources damage and publicdecision making has become a major topic of debate for the economic community [9], 
this is the most used method to valuate environmental damages [10,11, among several others]. According to [10], contingent valuation is a survey approach designed to create the missing market for public goods by determining what people are willing to pay for specific damage or to accept for compensation for well-specific degradation. Thus, as well as for other valuation approaches, the contingent valuation considers the premise of economic rationality, i.e. it considers exclusively the consumer viewpoint and ignores the production side (e.g. the natural resources and its processes). Additionally, as emphasized by [12], the use of stated preference valuation methods is necessarily sensitive to individual emotional concerns, resulting in high heterogeneity among individual's samples.

Alternatively to traditional economic approaches, the use of biophysical approaches to quantify environmental damages is increasing in scientific literature, in which eMergy accounting is receiving special emphasis. Emergy (spelled with an " $\mathrm{m}$ ") is "the available energy of one kind previously used up directly and indirectly to make a service or product" [5; p.7]. In accordance to the second law of thermodynamics, each transformation process degrades the available energy, but the "quality" of the remaining energy is increased. This important concept is considered within the emergy accounting framework under a donor side approach - instead of receiver side used by the economic approaches. A full description of emergy methodology, meanings and rules is beyond the scope of this paper, but deeper information are available at several published scientific works including, among others, the classical book of H.T. Odum [5].

Emergy can be considered as a scientific measure of real wealth in terms of the energy previously required to make something. Due to its ability in showing the real value under a donor side perspective by considering biophysical units rather than economic and subjective ones, emergy is used in this work to estimate the environmental damages caused by the oil spill incidents of Petrobras S.A. Brazilian Oil Company in 2000 yr. For this, the previous emergy evaluation of Exxon Valdez oil spill in 1991 done by [6] is used as reference for the emergy of damage estimation caused Petrobras S.A.; from this work, we have estimated an average value of 8.15E22 seJ representing the impacts on natural biome caused by 258,000 oil barrels spilled in 1991 during Exxon Valdez incident. The emergy per money ratio of Brazil in $2000 \mathrm{yr}$ of $7.80 \mathrm{E} 12 \mathrm{seJ} / \mathrm{USD}$ [13] is used to convert the emergy of damage from solar emjoules (seJ) into emdolars (EmUSD) units, which can be later compared to the values of environmental liabilities quantified under economical approach as published by [3]. It is worth to say that USD and EmUSD units should be understand as similar, in which the prefix "Em" expresses that calculation was done under emergy approach.

\section{$3 \quad$ Results and Discussion}

\subsection{Assessing Alternatives for Presenting the Environmental Liabilities into the Balance Sheet}

Table 1 shows the balance sheet as divulgated by Petrobras S.A. related to its performance in $2000 \mathrm{yr}$. It can be noted the lack of detailed information regarding the economic investment on prevention of environmental incidents in the "assets" group, 
as well as the absence of a detailed description of economical obligations in the "liabilities" group related to the environmental damages caused. It is worth to say the existence of laws (no. 9,605/1998) regarding the inclusion of these items into the company's balance sheet (CBS) at that time, which foresaw criminal responsibility for environmental impacts. The lacunae in Table 1 represented by symbol "?" indicates items that were not foreseen by the accounting regulation existing in 2000 $\mathrm{yr}$, thus they were not considered in the Baseline structure for the CBS evaluated. The existence of these lacunae highlights the inability of this CBS structure in showing clearly the company's liabilities - when considered! -, which disallow deeper evaluations about the company's economic performance by society and investors. For instance, the "total log-term obligation" item (which indicates the company's debts for long-time period) was 9,122,181 million USD, however no detailed information is provided regarding specificities of this amount, such as penalties, indemnities, funding, etc. The same comment can be done to "equity" of 13,802,668 million USD, in which no information is provided regarding the amount of "shareholder", "earning reserves", and "environmental result".

Table 1. Traditional (Baseline) annual balance sheet of Petrobras S.A. for $2000 \mathrm{yr}$ (values in 1,000 USD)

\begin{tabular}{|c|c|c|c|}
\hline Asset (A) & & Liabilities (B) & \\
\hline Total current assets & $11,670,386$ & Total current liabilities & $12,604,377$ \\
\hline Total LG receivables & $9,245,301$ & Total LG obligations & $9,122,181$ \\
\hline Permanent assets & & $?$ & ? \\
\hline Investments & $5,300,076$ & $?$ & $?$ \\
\hline Properties & $9,020,700$ & $?$ & ? \\
\hline$?$ & ? & Equity (C) & $13,802,668$ \\
\hline$?$ & $?$ & $?$ & ? \\
\hline$?$ & $?$ & $?$ & $?$ \\
\hline Deferred & 292,762 & $?$ & ? \\
\hline Total (A) & $35,529,227$ & Total $(\mathrm{B})+(\mathrm{C})$ & $35,529,227$ \\
\hline
\end{tabular}

LG = long-term

Table 2 shows the structure for CBS as suggested by [3]. This structure highlights several information regarding actions for environmental damages prevention, including investments of 300,546 million USD in environmental protection and damages prevention projects. It is also clear the amount of liabilities occurred by Petrobras S.A. due to the caused environmental damages, reaching a value of 1,602,681 million USD. The suggested CBS structure shows higher values for "total long-term obligations" than Table 1 (from 9,122,181 to 10,724,863 million USD), besides lower values for "equity" (from 13,802,668 to 12,199,987 million USD), which could lead to a negative image of company for investors, at least for short-time period. Under a general view, the suggested CBS structure by [3] as presented at Table 2 can be considered more objective and detailed than the Baseline CBS structure presented at Table 1, allowing better understanding by society and investors about where and how money is circulating within company's boundaries, mainly on the environmental-related aspects. 
Table 2. Modified (Alternative \#1) annual balance sheet of Petrobras S.A. for $2000 \mathrm{yr}$ (values in 1,000 USD)

\begin{tabular}{|c|c|c|c|}
\hline Asset (A) & & Liabilities (B) & \\
\hline Total current assets & $11,670,386$ & Total current liabilities & $12,604,377$ \\
\hline Total LG receivables & $9,245,301$ & Total LG obligations & $10,724,863$ \\
\hline Permanent assets & & Environmental provision & $1,602,681$ \\
\hline Investments & $5,300,076$ & Penalties & 122,950 \\
\hline Properties & $9,020,700$ & Indemnities & $1,479,730$ \\
\hline PEE & 300,546 & Equity $(\mathrm{C})$ & $12,199,987$ \\
\hline$E P P$ & $?$ & $?$ & ? \\
\hline$?$ & $?$ & $?$ & ? \\
\hline Deferred & 292,762 & $?$ & ? \\
\hline Total (A) & $35,529,227$ & Total $(\mathrm{B})+(\mathrm{C})$ & $35,529,227$ \\
\hline
\end{tabular}

Table 3. Improved (Alternative \#2) annual balance sheet of Petrobras SA for $2000 \mathrm{yr}$ (values in 1,000 USD)

\begin{tabular}{|c|c|c|c|}
\hline Asset (A) & & Liabilities (B) & \\
\hline Current assets & $11,670,386$ & Current liabilities & $12,604,377$ \\
\hline Noncurrent assets & $23,858,840$ & Noncurrent liabilities & $10,724,863$ \\
\hline $\begin{array}{ll}\text { LG } & \text { receivable } \\
\text { assets } & \end{array}$ & $9,245,301$ & Environmental provision & $1,602,681$ \\
\hline Investments & $5,300,076$ & Penalties & 122,950 \\
\hline Properties & $9,020,700$ & Indemnities & $1,479,730$ \\
\hline PEE & 300,546 & Equity $(\mathrm{C})$ & $12,199,987$ \\
\hline$E P P$ & ? & Shareholders & $8,251,100$ \\
\hline Intangibles & ? & Earnings reserve & $5,551,568$ \\
\hline Deferred & 292,762 & Environmental result & $-1,602,681$ \\
\hline Total (A) & $35,529,227$ & Total $(\mathrm{B})+(\mathrm{C})$ & $35,529,227$ \\
\hline
\end{tabular}

LG = long-term; PEE = Program for environmental excellence; $\mathrm{EPP}=$ Environmental performance projects

Table 3 shows the improved structure suggested for financial balance sheet, in which numbers are supplied according to modifications required by laws 11,638/2007 and 11,941/2009. This new structure for CBS includes all essential information for a deeper understand about company's economic performance. Besides highlighting the environmental liabilities as also suggested by Alternative \#1 (Table 2), this new structure goes a step forward by detailing other items in the "equity" group to make available and transparent for investors the numbers regarding the reduction of company's goods and services - since this aspect is already regulated by law $11,638 / 2007$. As a result, the item "environmental result" shows the value of 1,602,681 million USD, which allows an easy-to-understand interpretation about the real impact resulted from the caused environmental liabilities. Moreover, the direct relation between the investments in environmental programs presented in "assets" group (e.g. program for environmental excellence and environmental projects) and the 
"environmental results" shows a ratio of 1:5, suggesting that low investments in programs for environmental damages reduction could result in higher liabilities.

By comparing Tables 1, 2, and 3, it can be noted that CBS's total numbers are constant $(35,529,227$ million USD) because this work focuses on the CBS structure presentation. Table 2 shows that "equity" (12,199,987 million USD), which represents the company's economic power, is not detailed in that kind of CBS structure. On the other hand, Table 3 shows the existence of three items for "equity" group: (i) "shareholders", which indicates all money invested by shareholders; (ii) "earnings reserve", indicating the company's activity results; (iii) "environmental result". This last presents clearly the amount of money lost by company due to environmental damages. Inserting the item "environmental result" into the CBS represents, in an easy-to-understand way, the company's expense with environmental damage issues and its commitment in making this information as clear as possible.

Although recognizing that suggested Alternative \#2 for CBS could be considered as a better way to present the company's financial annual dynamics, there still are two lacunae containing the symbol "?": "EPP" and "intangibles". The first one was not considered because Petrobras S.A. had no investment value declared in $2000 \mathrm{yr}$. The second one ("intangibles") was not considered because this item was created by law no. 11,638 in 2007. "Intangibles" can be considered as a key aspect in this new structure for CBS, because it could provide higher capacity for company's indebtedness or even to overestimate its results according to market functioning. The company's indebtedness capacity can be increased as much as higher its "assets" value, thus the item "intangibles" plays important role because it is composed by the value of immaterial goods (i.e. the immaterial goods tends to be higher as much as higher the company's value in the market).

The CBS structure as suggested in this work by Table 3 aims to make available, in a clear way, all the information regarding the company's financial issues, as envisaged by the general principle of accounting. On the other hand, it must be highlighted that the effect of this kind of CBS structure on the investors' perception is not evaluated, for instance, the issues regarding the investor's confidence by investing in the company (low risk) and the consequent cash injection. However, the study of [4] has indicated a strong relation between a clear divulgation of company's liabilities and the investments reduction by shareholders. This is an important aspect because a clear communication about company's environmental liabilities could result, at a first moment, in a negative image of company by society and investors, but later it could push companies for higher investment in prevention programs of environmental damages. In short time periods, a negative image of companies and the increase of expenses with environmental programs could result in lower investments by shareholders and total earnings, but in long term, the consequent reduction of environmental damages allied to company's commitment in preventing them could result in a positive image and higher investments from shareholders. All these aspects are being considered more and more by [1] in the search for a more holistic company's financial report structure, in which using a systemic strategy could lead to the attraction of "faithful investors" for long time periods. In this scenario, the shares volatilization in the stock market would be strongly reduced as well as the risk in the investment. 


\subsection{Evaluating Alternatives to Quantify Environmental Damages in Economic Terms}

Table 4 shows the in-dollar values of environmental liabilities estimated by economic and emergy perspectives for the oil spill incidents of Petrobras SA in 2000. The emergybased values were estimated using the [6] numbers that have assessed the emergy related to the Exxon Valdez oil spill at Alaska in 1991. Two important aspects should be highlighted in this table: (i) the difference between the economic cost of 1,602 million USD (established by court and other national committees for the environment under a willing-to-pay and other subjective approaches) and emergy-based cost of 55 million EmUSD; (ii) the difference between the emergy-based cost associated exclusively to biota damage of 55 million EmUSD and its equivalent when accounting for all information associated after public pressure (3,170 million EmUSD).

Table 4. Estimative of economic and emergy costs related to oil spill incidents of Petrobras SA.

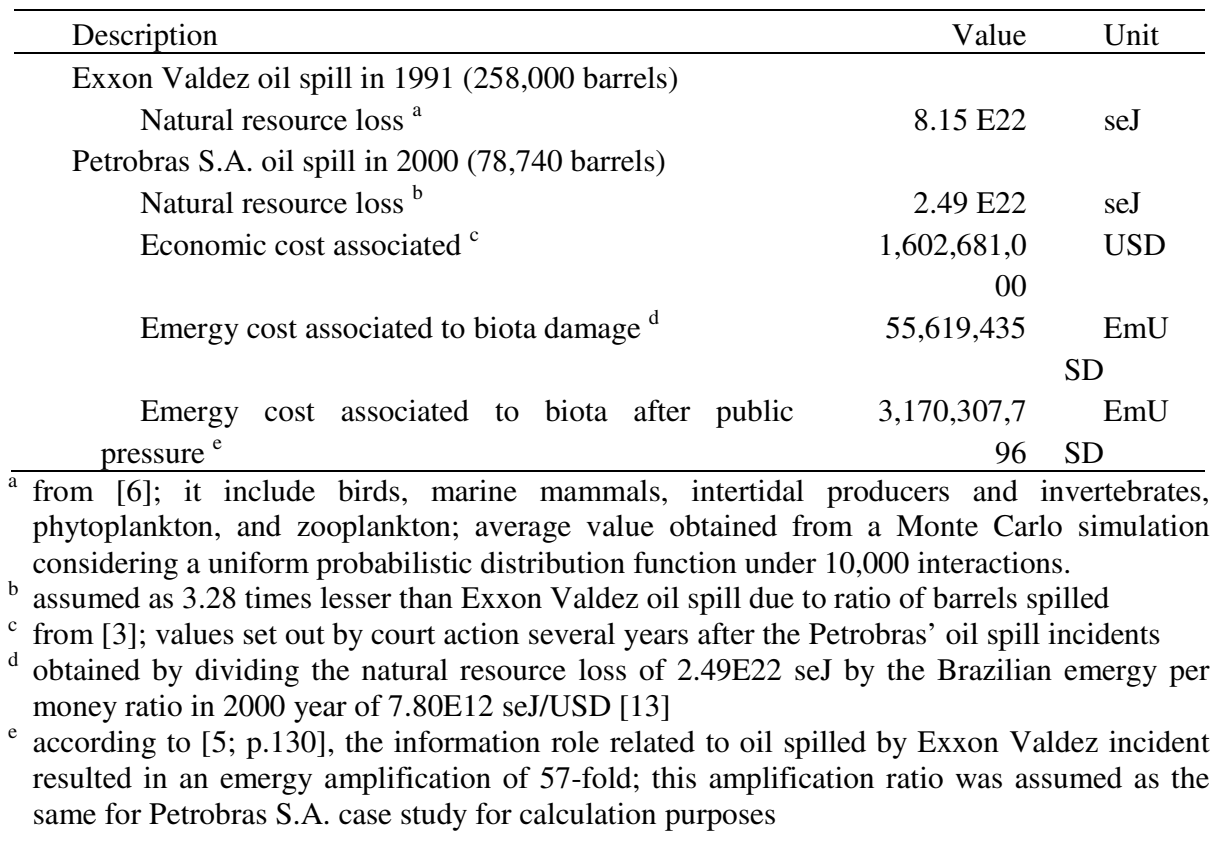

The three different estimated values for the environmental damages caused by Petrobras S.A. in $2000 \mathrm{yr}$ are important as a quantitative reference to be included in the CBS, within the item "environmental provision". Table 3 shows the Petrobras' balance sheet by including the liabilities as estimated under an economical view (1,602,681 million USD), resulting in a company's "equity" of 12,199,987 million USD. Now, considering the liabilities value as estimated under an emergy view $(55,619,435$ million USD), the "equity" is increased by $12.7 \%$ reaching $13,747,049$ million USD, resulting in higher credibility of company by investors and economic development. On the other hand, by considering the liability as estimated under emergy perspective after public pressure $(3,170,307,796$ million USD), the "equity" is 
reduced by $12.8 \%$ reaching $(10,632,360$ million USD), resulting in disrepute of company by investors and low economic development. As noted, the different approaches used to estimate the environmental liabilities result in different values for "environmental provision" item and different interpretation from investors for CBS.

According to [5], since half of the world's empower (emergy flow per unit time) comes from the renewable environment, the amplification value obtained for environmental liabilities after public pressure of 3,170,307,796 EmUSD might have been appropriated as a good opportunity to compensate the environmental damage, but mainly to educate companies avoiding future oil spill incidents. This goes in parallel with [11] statement in which, more than educational purposes, there is a need for complementary remediation to compensate for the loss of services during the restoration period. We recognize that there are still some conceptual barriers that must be overcome to reach consensus among the scientific community about the most suitable economic value that should be charged due to oil spill incidents (as well as for any other negative externality caused by different production systems), but emergy methodology suggest to be a powerful alternative which reflects the biophysical donor side perspective.

For those ones currently skeptics or not comfortable yet on using biophysical approaches to estimate monetary values, or even when dealing with practical difficulties regarding environmental liabilities valuation (for example the lack of primary data), [3] suggests that, at least, it must exist a detailed explicative footnote information in the CBS concerning the potential future charges of those liabilities.

\section{Conclusions}

(a) The suggested structure for company's financial balance sheet could be considered as more appropriated compared to other two assessed ones to show in detail the economical performance of companies, mainly regarding aspects related to environmental issues. Through this improved structure, society and investors can have better-based information about how company is operating or being managed and its concerns related to environmental damages. This structure brings more clarity about company's management and could result in a beneficial image to investors at long time periods.

(b) The quantification of environmental liabilities in economic terms claims for additional efforts among the scientific community. Defining the real objectives in estimating the economical compensation values should be the first criteria, i.e. establishing purposes for repairing the environmental damage or also including educational purposes. To exclusively repair the damage, the emergy-based approach could be applied, and for educational purposes, the amplified emergy values after public pressure seems to be a good alternative. We recognize that this issue still deserves a huge discussion, but we also recognize that using emergy accounting could be a better alternative compared to contingent valuation.

Acknowledgements. We are grateful to Dr. Carlos Alberto Di Agustini for his valuable comments. This work received financial support from the Vice-Reitoria de Pós-Graduação e Pesquisa of Universidade Paulista (UNIP). 


\section{References}

1. International Integrated Reporting Council, Consultation draft of the international $<\mathrm{IR}>$ framework, Integrated Reporting (2013),

http: / / www. theirirc.org/consultationdraft

2. Deegan, C.: The accounting will have a central role in saving the planet...really? A reflection on "green accounting and green eyeshades twenty years later". Critical Perspectives on Accounting 24, 448-458 (2013)

3. Bertoli, A.L.: Passivo ambiental: estudo de caso da Petróleo Brasileiro S.A. Petrobrás. A repercussão ambiental nas demonstrações contábeis em consequência dos acidentes ocorridos. Revista de Administração Contemporânea 10, 117-136 (2006) (in Portuguese)

4. Cormier, D., Magnan, M.: Investors' assessment of implicit environmental liabilities: An empirical investigation. Journal of Accouting and Public Policy 16, 215-241 (1997)

5. Odum, H.T.: Environmental accounting - emergy and environmental decision making. John Wiley \& Sons, Inc. (1996)

6. Whoite, R.D.: Emergy analysis of the T/V Exxon Valdez oil spill and alternatives for oil spill prevention. M.Sc. dissertation, University of Florida, USA (1992)

7. Ortega, E., Sarcinelli, O., Souza, P.B.M.: Combining bookkeeping techniques and emergy analysis. In: Brown, et al. (eds.) Proceedings of 3rd Biennial Emergy Research Conference, University of Florida, Gainesville, USA (2005)

8. Campbell, D.E.: Financial accounting methods to further develop and communicate environmental accounting using emergy. In: Brown, et al. (eds.) roceedings of 3rd Biennial Emergy Research Conference, University of Florida, Gainesville, USA (2005)

9. Carson, R.T., Flores, N.E., Meadle, N.F.: Contingent valuation: controversies and evidences. Environmental and Resource Economics 19, 173-210 (2001)

10. Carson, R.T., Mitchell, R.C., Hanemann, M., Kopp, R.J., Presser, S., Ruud, P.A.: Contingent valuation and lost passive use: damages from the Exxon Valdez oil spill. Environmental and Resource Economics 25, 257-286 (2003)

11. Martin-Ortega, J., Brouwer, R., Aiking, H.: Application of a value-based equivalency method to assess environmental damage compensation under the European Environmental Liability Directive. Journal of Environmental Management 92, 1461-1470 (2011)

12. León, C.J., Araña, J.E., Hanemann, W.M., Riera, P.: Heterogeneity and emotions in the valuation of non-use damages caused by oil spills. Ecological Economics 97, 129-139 (2014)

13. Sweeney, S., Cohen, M., King, D.M., Brown, M.T.: Creation of a global emergy database for standardize national emergy synthesis. In: Brown, et al. (eds.) Proceedings of 4th Biennial Emergy Research Conference, University of Florida, Gainesville, USA (2007) 